\title{
A basis for generating expectancies for verbs from nouns
}

\author{
KEN MCRAE \\ University of Western Ontario, London, Ontario, Canada \\ MARY HARE \\ Bowling Green State University, Bowling Green, Ohio \\ JEFFREY L. ELMAN \\ University of California San Diego, La Jolla, California \\ and \\ TODD FERRETTI \\ Wilfrid Laurier University, Waterloo, Ontario, Canada
}

\begin{abstract}
We explore the implications of an event-based expectancy generation approach to language understanding, suggesting that one useful strategy employed by comprehenders is to generate expectations about upcoming words. We focus on two questions: (1) What role is played by elements other than verbs in generating expectancies? (2) What connection exists between expectancy generation and event-based knowledge? Because verbs follow their arguments in many constructions (particularly in verb-final languages), deferring expectations until the verb seems inefficient. Both human data and computational modeling suggest that other sentential elements may also play a role in predictive processing and that these constraints often reflect knowledge regarding typical events. We investigated these predictions, using both short and long stimulus onset asynchrony priming. Robust priming obtained when verbs were named aloud following typical agents, patients, instruments, and locations, suggesting that event memory is organized so that nouns denoting entities and objects activate the classes of events in which they typically play a role. These computations are assumed to be an important component of expectancy generation in sentence processing.
\end{abstract}

The role of expectancy generation in sentence processing has attracted increased attention over the past several years. There has long been reason to believe that comprehenders generate expectations about upcoming words as they process sentences presented incrementally (Kutas \& Hillyard, 1984; Marslen-Wilson \& Welsh, 1978), and computational modeling suggests that implicit expectancy generation can lead to the discovery of underlying syntactic structure (Elman, 1990). More recently, a number of researchers have suggested that although language understanding is clearly about more than simply anticipating what comes next, expectation does appear to play a critical role in language processing (Altmann, 2002; Federmeier \& Kutas, 1999; Van Berkum, Brown, Zwitserlood, Kooijman, \& Hagoort, 2005; Wicha, Moreno, \& Kutas, 2003). Two questions that immediately arise are the following: (1) Which elements in a sentence can be used to gener-

This work was supported by NIH Grant MH6051701 to the first three authors and NSERC Grant OGP0155704 to the first author. Correspondence concerning this article should be addressed to K. McRae, Department of Psychology, Social Science Centre, University of Western Ontario, London, ON, N6A 5C2 Canada (e-mail: mcrae@uwo.ca). ate expectancies? and (2) What connection exists, if any, among expectancy generation, higher levels of understanding (e.g., event knowledge), and the extraction of meaning? In what follows, we will sketch a response to these questions, arguing that verbs are an important source of expectancy generation but that sentential nouns can be so as well, via the activation of generalized event knowledge. We tested this hypothesis with a set of priming experiments.

\section{Expectancy Generation From \\ Verbs and Nonverbs}

In response to the first question, it is clear that verbs play a central role in sentence processing and, by logical extension, are likely to be powerful generators of expectancies. Nouns may stand alone, but verbs rarely do. As predicating functions, verbs exhibit regular and systematic restrictions on their complements. Although verbs as a category enter a child's language later than do nouns, they are associated with the first appearance of real grammar. From that point on, it is clear that verbs play the major role in organizing the event structure that underlies sentences (Gentner, 1982; Tomasello, 1992).

Among other things, a verb imposes syntactic constraints on the phrases with which it co-occurs (its argu- 
ments), as well as semantic constraints, such as the thematic roles it assigns to those arguments. Experimental work has demonstrated that these restrictions influence comprehension (among numerous other findings, see those in Boland, Tanenhaus, Carlson, \& Garnsey, 1989; Carlson \& Tanenhaus, 1988; Ferreira \& Clifton, 1986; Frazier, 1987; Frazier, Clifton, \& Randall, 1983; Rayner, Carlson, \& Frazier, 1983; for a review, see Tanenhaus \& Trueswell, 1995). Clearly, there are a myriad of ways in which verbs lie at the heart of sentence processing.

Furthermore, it is clear that the information available from verbs is remarkably fine-grained both structurally and semantically and that this information interacts in complex ways with other cues in the sentence (Altmann, 1998, 1999; MacDonald, Pearlmutter, \& Seidenberg, 1994; McRae, Ferretti, \& Amyote, 1997). For this reason, computational models have proven to be invaluable tools both in understanding the empirical phenomena and in uncovering the deeper principles that guide processing (Christiansen \& Chater, 1999; Elman, Hare, \& McRae, 2004; Spivey-Knowlton \& Tanenhaus, 1998; Tabor \& Tanenhaus, 2001). One of the major lessons of this computational modeling is that - in these models, at least - a sentential element's effect on processing does not depend directly on its grammatical category but, instead, reflects that element's predictive value. Given that verbs are a powerful source of constraint, as a category, they can be expected to loom large in the guiding of processing. But the verb may not be the only element in the sentence that plays this role. Nouns, prepositions and adjectives possess valence restrictions, for example, although to a weaker degree than do verbs. Thus, words from other major syntactic categories may exert constraining forces as well.

There are at least two reasons to believe that this possibility is exploited in language comprehension. First, if the verb alone determines the roles played by other elements in the sentence, the depth to which the sentence can be processed will be limited pending the verb's appearance. However, there are languages, such as German and Japanese, in which the verb often appears in clause- or sentence-final position. A computational mechanism that defers any hypothesis about structure and meaning until the end of the clause or sentence would be highly inefficient (Frazier, 1987) and inconsistent with the results of studies showing that information is rapidly and incrementally integrated as a sentence is processed (MarslenWilson, 1975; Tanenhaus, Spivey-Knowlton, Eberhard, \& Sedivy, 1995). Indeed, recent studies suggest that incremental syntactic processing does occur in verb-final constructions in German and Japanese (Kamide \& Mitchell, 1999; Kamide, Scheepers, \& Altmann, 2003). Thus, at the very least, nonverb elements must play some role in such languages in generating hypotheses about the ultimate structure.

Second, many psycholinguistic experiments have demonstrated that the assignment of thematic roles in sentences involves a complex interaction between the verb and the nonverb elements. For example, the goodness of fit of specific noun phrases (NPs) with the verb's thematic roles influences the interpretation of temporary ambiguities (MacDonald, 1994; McRae, Spivey-Knowlton, $\&$ Tanenhaus, 1998). The influence is not limited to the nouns serving as the verb's arguments: Adjectival modifiers (shrewd heartless gambler vs. young naive gambler) can influence the interpretation of a noun as either a good agent or a good patient of its verb (manipulated) and, consequently, can influence the interpretation of a temporarily ambiguous structure (McRae et al., 1997).

Even more strikingly, the extent to which an NP may be a good fit for a thematic role may depend not only on the verb, but also on the other arguments (Altmann, 1999; Kamide, Altmann, \& Haywood, 2003). In a head-mounted eye-tracking study, Kamide et al. (2003) showed that the preferred patient for the verb ride varied as a function of the agent NP: On hearing the girl will ride, participants preferentially looked at a picture of a carousel, but after the man will ride, they looked more often at a motorbike. These results are particularly challenging for traditional theories of verb representation. It is difficult enough to imagine how to encode the fine-grained nature of verbspecific role/filler expectations in traditional symbolic accounts in which the representation includes only a finite set of verb-general thematic roles, such as agent (Fillmore, 1968; Gruber, 1965). It is even harder to envision how to capture the higher order contingencies by which one argument determines the goodness of fit of another. In other words, these results are difficult to interpret within a framework in which the verb is the sole generator of a comprehender's expectancies.

Thus, with regard to the first question-Which elements in a sentence can be used to generate expectancies?-we conclude that there is good evidence to believe that nonverb elements may play an important role. We turn now to the second question: What connection exists, if any, among expectancy generation, higher levels of understanding, and the extraction of meaning?

\section{Expectancy Generation and Event Knowledge}

One possibility, consistent with the two-stage serial models (Ferreira \& Clifton, 1986; Frazier, 1987; Frazier, et al., 1983), is that predictive processing is driven strictly by low-level heuristics that are sensitive only to coarsegrained information, such as grammatical category and syntactic relationships. The other possibility, consistent with constraint-based probabilistic models (Altmann, 1999, 2002; MacDonald, 1994; McRae et al., 1998; Trueswell, Tanenhaus, \& Garnsey, 1994), is that there may be significant interactions between, for example, lexical and world knowledge information and that, therefore, predictive processing is sensitive to syntactic, semantic, and pragmatic constraints.

This view is broadly consistent with those of researchers who have stressed the role of situation models in language comprehension (e.g., Garrod \& Sanford, 1981; Kamide et al., 2003; Potts, Keenan, \& Golding, 1988; Vu, Kellas, Petersen, \& Metcalf, 2003). The interaction of lexical and world knowledge also is consistent with the view of thematic roles developed recently by McRae and colleagues 
(Ferretti, McRae, \& Hatherell, 2001; McRae et al., 1997), who proposed that thematic role assignment involves detailed experiential knowledge that is highly specific to events denoted by individual verbs. As in Dowty (1991), a thematic role is considered to be a concept with internal structure. But on McRae's account, role concepts are formed not from a limited set of verb-general features, but through everyday experience with the entities and objects that play specific roles in specific types of events. This view concurs with recent linguistic characterizations of thematic roles in claiming that they are verb specific (e.g., Sag \& Wasow, 1999) but differs in viewing them as more than simply lexical information. One's concept of the agent role of accuse, for example, is formed by generalizing over experiences with those who accuse others (experienced either directly or through linguistic descriptions of the event). This conceptual/world knowledge is then computed and used immediately in online language processing. Note that higher level, verb-general aspects of thematic roles, as in Dowty, follow from this account as well, because they can be described as emerging through the conspiracy of many idiosyncratic thematic role representations of related verbs (see McRae et al., 1997, for further discussion).

One prediction of this account is that verbs, as they are accessed, should immediately activate highly specific knowledge about the entities that typically participate in the event that they encode. Ferretti et al. (2001) tested this in a series of priming experiments demonstrating that verbs primed agents, patients, and instruments that were typical role fillers for those verbs (although they did not find priming for typical locations). These results are consistent with the claim that when the verb is encountered, the activated representation includes knowledge of the event that it denotes. This event knowledge then drives the priming of the nouns, which are verbal labels for salient participants in the activated event memory.

Consistent with the literature on the organization of autobiographical event memory (Anderson \& Conway, 1997; Reiser, Black, \& Abelson, 1985), this account also predicts that verbs are not the sole source of constraint. The event - encoded linguistically through the verb - clearly is central in organizing and accessing the associated knowledge (Kolodner, 1984; Schank, 1982). But the knowledge of a generalized event, such as skating or accusing, can be computed and accessed in multiple ways (Brown \& Schopflocher, 1998; Lancaster \& Barsalou, 1997). For example, in offline studies, Lancaster and Barsalou found that comprehenders are adept at organizing short narratives in terms of multiple components of events. Activity (i.e., the verb) is an important component, but time, location, and participants, such as the agent and patient, are important as well.

Thus, if knowledge of the roles associated with a verb is event knowledge, nouns denoting salient participants should also quickly activate well-learned event knowledge and, in doing so, should predictively activate the corresponding verb. More precisely, we assume that a concept or class of concepts (rather than a specific word) will be activated, and priming will occur if the target verb overlaps substantially with the predicted event space. ${ }^{1}$

\section{Goals}

The experiments presented below were designed to test whether a single noun (stripped from sentence context) can lead to the computation of information concerning a class of events. Although our experiments involve word-word priming only, these results would be consistent with the literature showing that as a sentence is read or heard, comprehension is based on the rapid incremental integration of the information from incoming words (Tanenhaus et al., 1995; Vu et al., 2003). As such, we see this work as bridging the gap between theories of sentence processing and those of lexical-semantic processing: A participant's performance on word-word priming tasks reflects the semantic information that is computed when a word is read or heard, and it is reasonable to assume that this same information is also computed when people read normal connected text or hear connected speech. Although researchers such as Kahan, Neely, and Forsythe (1999) refer to a prime as "providing a semantic context that 'sets the stage' for the target's processing" (p. 105), it has been unusual to use word-word priming studies to draw inferences regarding online sentence comprehension. However, one advantage of the priming task is that it represents a lower bound on the information available to the comprehender by eliminating constraints offered by the other nouns in the sentence, case marking, context, and so on. Word-word priming, as a measure of what is activated in the absence of other constraints, thus offers a stringent test for studying these phenomena.

\section{EXPERIMENT 1}

In Experiment 1, we used short stimulus onset asynchrony (SOA; the time between the onset of the prime and the onset of the target) priming from nouns to verbs to test the predictions of the event-based account. The noun primes refer to typical fillers of the thematic roles of the verb that describes the event - that is, the agents, patients, or instruments that are typically involved in the event denoted by the target verb or the locations at which the event typically occurs. Short-SOA priming was used because it is assumed to provide a window into the organization of semantic memory, with effects being uncontaminated by strategic processing, particularly when pronunciation latency is the dependent measure. Studies such as those of de Groot (1984), den Heyer, Briand, and Dannenbring (1983), and Stolz and Neely (1995) have shown that explicit expectancy-based priming does not occur with SOAs of $250 \mathrm{msec}$ or less. Note that this type of explicit expectancy generation, often viewed in terms of generating a set of possible ensuing words, as in Becker's (1980) verification model, differs from the type of implicit expectancy generation that is believed to occur in normal sentence processing (Altmann, 2002; Elman, 1990; Federmeier \& Kutas, 1999). We predicted shorter naming latencies for verbs primed by their typical thematic role fillers than for 
verbs primed by unrelated nouns, on the assumption that the related noun will activate knowledge of an event in which it typically participates, thus facilitating processing of the verb denoting that generalized event.

\section{Method \\ Participants. Forty University of Western Ontario undergradu-} ates participated in the priming experiment for course credit. All the participants were native speakers of English and had normal or corrected-to-normal visual acuity.

Materials. To tap comprehenders' knowledge of the types of events in which certain entities and objects play a specific role, we used what we will refer to as thematic-based event generation norms. These norms are designed to estimate the conditional probability of a generalized event, given an entity or object playing a specific role. Participants were asked to generate verbs in response to typical agents, patients, instruments, and locations. In the agent norms, the participants were given nouns such as nun and were asked to "list the things that these people commonly do." In the patient norms, the participants were given nouns such as guitar and were asked to "list the things that these objects/people commonly have done to them." In the instrument norms, participants were given nouns such as crayon and were asked to "list the things that people commonly use each of the following to do." Finally, in the location norms, the participants were given nouns such as cafeteria and were asked to "list the things that people commonly do at/in each of these locations." For each item, space was provided for 10 responses. No time limit was imposed. The participants were undergraduate students from Bowling Green State University. Each participant completed only one list (i.e., only for one of agents, patients, instruments, or locations); there were approximately 25 items per list. In total, 20 participants responded to each item.

Note that by design, we did not conduct word association norms for choosing the items for these experiments. On the one hand, responses in such norms have a strong tendency to be members of the same grammatical category as the stimulus: Noun stimuli are likely to elicit nouns, verbs to elicit verbs, and so on. Since our primetarget pairs come from different grammatical categories, few would likely show up as associated by this criterion. Hence, conducting word association norms with these items may not have been informative or compelling. More important, participants' performance on the word association task is driven by a number of other factors, including their knowledge of semantic relations and the ways in which words co-occur to express these relationships. In some ways, then, our thematic-based event generation norms are a version of a word association task: We provided participants with a word stimulus and asked them to produce a linguistic response. The key difference, however, is that our norms targeted specific types of semantic relations, and the responses reflected these underlying relationships, not simply undifferentiated associations.

Responses in the event generation norms were scored on the basis of their rank order within a participant and on their response frequency. That is, each response was scored in terms of the number of participants listing it 1 st, $2 \mathrm{nd}, 3 \mathrm{rd}$, through to 10 th. A weighted score was calculated for each response by multiplying the frequency with which it was produced as the first response times 10, second times 9 , and so on, and then summing those products. Wherever possible, noun-verb pairs were chosen for the priming experiment by taking the verb with the highest weighted score. In a few cases, the response with the highest weighted score could not be used because it was a multiword phrase, such as play hockey for arena, and the constraints of the naming task demanded a single-word verb target. In a few other cases, the same verb was the best response for more than one item (e.g., cut for both chainsaw and knife) or was too general to serve as an appropriate prime (sees). When the best item could not be used, we chose either another highly ranked response or a synonym or near synonym of the best response.
From these norms, we chose 30 agents paired with the present participle of a verb, such as nun-praying, waiter-serving, and lawyer-defending; 30 patients paired with the past participle form of a verb, such as guitar-strummed, teeth-brushed, and tax-paid; 32 instrument-present-participle pairs, such as crayon-coloring, pen-writing, and chainsaw-cutting; and 24 location-presentparticiple pairs, such as cafeteria-eating, bedroom-sleeping, and bathroom-showering (all the items are presented in the Appendix). The weighted scores for the verbs for each thematic role were the following (maximum of 200): agents, $M=104, S E=8$; patients, $M=115, S E=9$; instruments, $M=145, S E=8$; and locations, $M=131, S E=9$.

Target verbs were presented in present participle form with the agent, instrument, and location primes. Verb targets paired with typical patients were presented in their past participle forms to avoid including prime-target pairs that formed coherent familiar phrases, such as cigar smoking.

Lists. Two lists were created for each role (i.e., agents, patients, instruments, and locations). Each list contained half of the targets paired with related primes and the other half of the targets paired with unrelated primes. Unrelated prime-target pairs were created by re-pairing the nouns and verbs from the related trials in the opposite list (e.g., praying was preceded by nun in List 1 of the agents and by sniper in List 2). Filler trials consisted of unrelated noun-verb pairs, such as magician-petting. Each list contained four times as many unrelated filler trials as related target items (relatedness proportion was .17 , which is quite low for studies of this sort). Thirty-five unrelated practice trials were used for the practice session for every participant. No participant saw any word twice.

Procedure. For each trial, the participant was instructed to silently read the first word presented on the computer screen and to pronounce aloud the second word as quickly and accurately as possible into the microphone. The stimuli were presented on a color monitor connected to a Macintosh computer using PsyScope (Cohen, MacWhinney, Flatt, \& Provost, 1993). A microphone connected to a CMU button box measured naming latency in milliseconds as the time between the onset of the target and the onset of the participant's pronunciation of it. Each trial consisted of the following: a focal point (*) for $250 \mathrm{msec}$; the prime for $200 \mathrm{msec}$; a mask

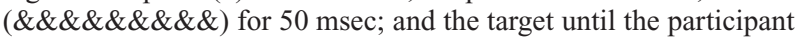
named it. ${ }^{2}$ The intertrial interval was $1,500 \mathrm{msec}$, and a break was given every 40 trials. Testing sessions began with the practice trials and lasted approximately $20 \mathrm{~min}$. The experimenter recorded trials in which the participant mispronounced a word (a pronunciation error), extraneous noise caused the voice key to trigger (a machine error), or the voice key failed to trigger (a machine error). The participants were assigned randomly to be tested on either the agents and locations or the patients and instruments. The order of the two lists was counterbalanced across participants (i.e., 10 participants were tested on agents and then locations and another 10 on locations and then agents, and the same for the patients and instruments).

Design. Naming latencies and the square root of the number of pronunciation errors (Myers, 1979) were submitted to separate twoway ANOVAs for each thematic role (agents, patients, instruments, and locations). The factor of interest was relatedness (related vs. unrelated), which was within both participants $\left(F_{1}\right)$ and items $\left(F_{2}\right)$. List was included as a between-participants dummy variable and item rotation group as a between-items dummy variable in order to stabilize variance that might result from rotating participants and items over the two lists (Pollatsek \& Well, 1995).

\section{Results and Discussion}

Naming latencies greater than three standard deviations above or below the grand mean were replaced by that value ( $1 \%$ of the trials). Two participants were dropped because their soft speaking style resulted in an extreme number of trials in which the voice key was not activated. 
Machine errors, the majority of which were caused by the microphone's failing to register the participant's response, occurred on $4 \%$ of the trials and were excluded from all analyses. Pronunciation errors were excluded from the latency analyses. Mean naming latency and percentage of pronunciation errors are presented for each condition in Table 1 . Verbs were named more quickly when preceded by a related versus an unrelated noun for each of the four thematic roles [agents, $F_{1}(1,18)=6.19, p<.05$, and $F_{2}(1,28)=4.12, p<.06$; patients, $F_{1}(1,18)=7.54$, $p<.05$, and $F_{2}(1,28)=11.98, p<.001$; instruments, $F_{1}(1,18)=5.66, p<.05$, and $F_{2}(1,30)=7.64, p<.01$; locations, $F_{1}(1,18)=5.33, p<.05$, and $F_{2}(1,22)=10.41$, $p<.01]$. There were no reliable differences in pronunciation error rates (all $F \mathrm{~s}<1$ ).

In Experiment 1, noun-verb pairs were chosen using thematic-based event generation norms designed to tap into comprehenders' knowledge of the conditional probability of a generalized event, given an agent, patient, instrument, or location. Significant noun-verb priming was obtained in all four cases. We take these results as evidence that this event knowledge allows a comprehender to generate expectancies for upcoming concepts in the language stream - in this case, for ensuing verbs.

One question that remains is whether these results could be due to word association. Here, we note that in the most general sense of association - that is, the relationship between things or words that are temporally or spatially contiguous in the world or in language-our stimuli are, of course, associated. The thematic-based event generation norms used to choose the stimuli were designed to tap into people's knowledge of events in the world - namely, knowledge of the types of events that involve specific types of agents, patients, instruments, and locations. The actions described by the verb and aspects of those actions described by these nouns are clearly associated in this sense, and multiple experiences of related associations of this sort are instrumental in the learning of event knowledge. Crucially, however, we argue that what is learned is not simple associations; instead, the learner bootstraps from the experience of these repeated contiguities to knowledge of the meaningful relationship that underlies them.
In summary, our items certainly are associated in the general sense of association; they are bound together through co-occurrence in real-world events and in linguistic descriptions of those events. This does not, however, contradict the claim that the pairs are salient examples of specific types of event-based relations. Further issues concerning word association and spreading activation networks will be discussed in the General Discussion section.

Finally, it should be pointed out that Ferretti et al. (2001) found robust priming from verbs to nouns referring to their typical agents, patients, and instruments. This raises the possibility that the present results might have been due to backward priming from the verb. If this were the case, it would seriously reduce the theoretical import of our results (they would be a recapitulation of Ferretti et al.'s results). A number of researchers have investigated backward priming, using compounds (e.g., priming from hop to bell) and items for which the prime-target versus target-prime word association strengths differ. For example, Kahan et al. (1999) and Peterson and Simpson (1989) have shown that backward priming with such items may occur in a naming task at a short SOA, such as that used in Experiment 1, but not at an SOA of $500 \mathrm{msec}$ (although they seem to occur at both SOAs for lexical decision). Therefore, Experiment 2 was a replication of Experiment 1 , using a $500-\mathrm{msec}$ SOA. If verbs are primed, we can conclude that backward priming was not responsible for the Experiment 1 results. It should be noted that a lack of priming at a $500-\mathrm{msec}$ SOA is unlikely for our items, given the strength of noun-verb relationships as measured by the thematic-based event generation norms.

\section{EXPERIMENT 2}

Experiment 2 replicated Experiment 1, using a long SOA. Again, we predicted shorter naming latencies for verbs primed by their typical thematic role fillers than for verbs primed by unrelated nouns, thus demonstrating that the Experiment 1 results were not due to backward priming from the verb.

\section{Method}

Participants. Sixty-eight undergraduates at Bowling Green State University participated for course credit. All the participants were

Table 1

Mean Verb-Naming Latencies (in Milliseconds) and

Percentages of Pronunciation Errors, Experiment 1

\begin{tabular}{|c|c|c|c|c|c|c|c|c|}
\hline \multirow[b]{2}{*}{ Dependent Measure } & \multicolumn{2}{|c|}{ Agents } & \multicolumn{2}{|c|}{ Patients } & \multicolumn{2}{|c|}{ Instruments } & \multicolumn{2}{|c|}{ Locations } \\
\hline & $M$ & $S E$ & $M$ & $S E$ & $M$ & $S E$ & $M$ & $S E$ \\
\hline \multicolumn{9}{|l|}{ Response latency } \\
\hline Unrelated & 592 & 21 & 583 & 20 & 565 & 20 & 578 & 16 \\
\hline Related & 574 & 19 & 561 & 18 & 549 & 17 & 560 & 19 \\
\hline Facilitation & $18^{*}$ & & $22^{*}$ & & $16^{*}$ & & $18^{*}$ & \\
\hline \multicolumn{9}{|l|}{ Percentage of errors } \\
\hline Unrelated & 1.9 & 0.8 & 3.2 & 1.4 & 1.4 & 0.7 & 2.5 & 1.2 \\
\hline Related & 1.9 & 0.9 & 1.9 & 0.8 & 1.1 & 0.6 & 1.5 & 0.8 \\
\hline Facilitation & 0 & & 1.3 & & 0.3 & & 1.0 & \\
\hline
\end{tabular}

*Significant by participants and items. 
native speakers of English and had normal or corrected-to-normal visual acuity.

Materials. Primes, targets, fillers, and practice items were identical to those in Experiment 1.

Procedure. The procedure differed from that in Experiment 1 in only two respects. First, the SOA was $500 \mathrm{msec}$, so that each trial now consisted of the following: a focal point (*) for $250 \mathrm{msec}$; the prime for $200 \mathrm{msec}$ (as in Experiment 1); a blank screen for $300 \mathrm{msec}$; and the target until the participant named it. Second, lists were now fully between participants. The participants were randomly assigned to be tested on either List 1 or List 2 of one of the four roles. Sixteen participants were tested on each of the agents, instruments, and locations ( 8 per list), whereas 20 participants ( 10 per list) were tested on the patients.

Design. The design was identical to that in Experiment 1.

\section{Results and Discussion}

Naming latencies greater than three standard deviations above or below the grand mean were replaced by that value ( $1 \%$ of the trials). One participant was dropped and replaced because of experimenter error. There were two trials with machine errors (caused when the microphone failed to register the participant's response), and these were excluded from all analyses. Pronunciation errors again were excluded from the latency analyses.

Mean naming latency and percentage of pronunciation errors are presented for each condition in Table 2. Verbs were named more quickly when preceded by a related versus an unrelated noun for each of the four thematic roles [agents, $F_{1}(1,14)=4.99, p<.05$, and $F_{2}(1,28)=4.85$, $p<.05$; patients, $F_{1}(1,18)=4.99, p<.02$, and $F_{2}(1,28)=$ $6.99, p<.02$; instruments, $F_{1}(1,14)=9.17, p<.01$, and $F_{2}(1,30)=8.50, p<.01$; locations, $F_{1}(1,14)=5.76, p<$ .05 , and $\left.F_{2}(1,22)=4.31, p<.05\right]$. The only reliable difference in error rates was in the instruments, and then only in the item analysis [instruments, $F_{1}(1,14)=2.08, p>.1$, and $F_{2}(1,30)=5.57, p<.05$; agents, $F_{1}(1,14)=3.15$, $p>.1$, and $F_{2}(1,28)=3.41, p>.07$; patients, $F_{1}(1,18)=$ 1.04 , and $\left.F_{2}(1,28)=2.31, p>.1\right]$. There were no pronunciation errors for the locations.

The goal of Experiment 2 was to test whether the Experiment 1 results were due to backward priming from verbs to typical role fillers; if this had been so, no priming should have been found in Experiment 2. The fact that significant verb priming effects of magnitudes similar to those in Experiment 1 obtained in all four cases shows that the priming indeed occurred from the nouns to the verbs.

\section{GENERAL DISCUSSION}

Understanding language involves constantly updating a situation model that represents what is being described as the linguistic input unfolds over time (Sanford \& Garrod, 1981). Researchers have argued that one element of this process is generating expectancies of the classes of concepts that ensue in speech or text (Elman, 1990; Kamide et al., 2003). A number of studies have focused on the variety of expectancies that may be generated from the verb, with verbs allotted a central role precisely because they often provide strong structural and semantic constraints (Altmann \& Kamide, 1999; Garnsey, Pearlmutter, Myers, \& Lotocky, 1997). In contrast, we have presented two sets of experiments to provide evidence that event-based expectancies might be generated from elements of a sentence other than a verb. Noun-verb pairs were chosen, using thematic-based event generation norms designed to tap into people's knowledge of the conditional probability of a generalized event, given an agent, patient, instrument, or location. In word-word priming experiments, agents, patients, instruments, and locations primed verbs that denote events for which they are typical. Experiment 1 was a short-SOA priming study, the type of study that is assumed to provide insight into the organization of memory. Priming obtained in all four cases. Given that it was crucial to establish that the priming occurred from agents, patients, instruments, and locations to verbs, rather than in the other direction, Experiment 2 tested for backward priming. With a longer SOA, significant priming effects similar in magnitude to those in Experiment 1 were obtained. Together, these experiments suggest that people's memory for generalized events is organized in such a manner as to promote expectancy generation from nouns to verbs in online sentence comprehension, provided that those nouns serve as sufficiently strong cues to those events.

These results are consistent with those in other priming studies that have been interpreted in terms of event memory. The results of Ferretti et al. (2001), described above, illustrate one such case. A second example comes

Table 2

Mean Verb-Naming Latencies (in Milliseconds) and

Percentages of Pronunciation Errors, Experiment 2

\begin{tabular}{|c|c|c|c|c|c|c|c|c|}
\hline \multirow[b]{2}{*}{ Dependent Measure } & \multicolumn{2}{|c|}{ Agents } & \multicolumn{2}{|c|}{ Patients } & \multicolumn{2}{|c|}{ Instruments } & \multicolumn{2}{|c|}{ Locations } \\
\hline & $M$ & $S E$ & $M$ & $S E$ & $M$ & $S E$ & $M$ & $S E$ \\
\hline \multicolumn{9}{|l|}{ Response latency } \\
\hline Unrelated & 584 & 31 & 542 & 25 & 555 & 20 & 540 & 20 \\
\hline Related & 568 & 28 & 520 & 19 & 533 & 15 & 527 & 19 \\
\hline Facilitation & $16^{*}$ & & $22^{*}$ & & $22^{*}$ & & $13^{*}$ & \\
\hline \multicolumn{9}{|l|}{ Percentage of errors } \\
\hline Unrelated & 2.4 & 0.5 & 2.3 & 0.5 & 4.6 & 0.5 & 0 & 0 \\
\hline Related & 0.3 & 0.8 & 4.0 & 0.6 & 2.5 & 0.5 & 0 & 0 \\
\hline Facilitation & 2.1 & & -1.7 & & 2.1 & & 0 & \\
\hline
\end{tabular}

*Significant by participants and items. 
from Moss, Ostrin, Tyler, and Marslen-Wilson (1995), who investigated a variety of semantic relations and found priming for instrument (broom-floor) and script (restaurant-wine) relations. We recently have extended these results in short-SOA priming experiments that appear to be interpreted best as arising from event representations (Hare, McRae, Friedrich, Kelly, \& Thomson, 2005). Nouns denoting events primed types of people and things that are typically part of those events; location nouns primed people and things that are typically found at those locations; and instrument nouns primed things on which those instruments are typically used.

\section{An Alternative Explanation}

Although we used word-word priming to argue that semantic memory is structured to support expectancy generation during comprehension, we also note that priming results of this type have often been described in terms of spreading activation in a semantic network. This raises the issue of whether spreading activation networks could predict the priming of verbs from agents, patients, instruments, and locations. Here, we will consider three instantiations of a spreading activation network and will argue that none offers a compelling alternative to an event memory account.

First, although the original semantic networks focused solely on noun representations (Collins \& Quillian, 1969), relatively early extensions incorporated verbs (Gentner, 1975; Rumelhart \& Levin, 1975). Verb representations in these models included core meaning plus thematic links to nodes that stood as placeholders for possible noun phrases that fill those roles in sentences. These links could be bidirectional, allowing activation to spread from the thematic role nodes to the verb node (and so allowing for noun-verb priming). However, the thematic links and nodes in such models would be insufficient to account for our results, because they included only minimal semantic content, limited to general selectional restriction information. The thematic link between a verb and an agent node might specify that the filler of that node must be animate, but nothing more detailed or item specific. Our experiments, on the other hand, controlled for general selectional restrictions: The primes in both the related and the unrelated trials were equivalent in animacy. The factors that they differed on (and that determined the results) were more subtle and item specific. Thus, a spreading activation model limited to general selectional restrictions would incorrectly predict no priming in the present experiments.

A second way in which spreading activation networks might predict priming from typical thematic role fillers to verbs is through undifferentiated links encoding associative relatedness. If the representations of words and/or concepts that often co-occur in events and language become linked (whether in semantics, orthography, and/or phonology) through an unspecified associative relation, those links could serve as the basis for priming from nouns referring to typical components of events to verbs. However, our study forms part of a larger pattern of empirical results, many of which appear to be inexplicable without recourse to event representation. Truitt and Zwaan (1997), for example, found that the word hammer was primed more strongly (with shorter naming times and faster recognition) after a sentence including a verb marked with imperfective aspect (He was pounding the nail) than after one with perfect aspect (He pounded the nail). This difference occurred, presumably, because the imperfective aspect presents an event as ongoing, whereas the perfect aspect presents an event as already completed. These results, which demonstrate that the interaction between the temporal properties of events and verb aspect influences the activation of world knowledge about events during sentence comprehension, would be very difficult to explain on an undifferentiated word-associative account.

Ferretti (2000) also manipulated verb aspect to reference various components of the temporal structure of events, hypothesizing that if an event is presented in the imperfective and, thus, as in the process of occurring, the location at which the event is taking place should be more salient than if it is presented in the perfect, which, by focusing on the resultant state, references the event as completed. In other words, if someone was in the process of skating, he or she is at the arena. In contrast, if someone had already skated, that person could then be at any location. In a short-SOA priming task, typical locations (e.g., arena) were significantly primed by verbs presented in their imperfective aspect (was skating), whereas no priming obtained when perfect aspect (had skated) was used. Again, these results follow naturally from, and the experiment was inspired by, an account in which priming occurs via event schemas. However, accounting for them in a spreading activation network would require incorporating some mechanism by which aspect can modulate the flow of activation.

In a similar vein, Ferretti et al. (2001) showed that the grammatical cues of active versus passive voice modulate computation of event-based knowledge. In Experiment 4, participants heard sentence fragments such as She arrested the or She was arrested by the and pronounced aloud visually presented targets, such as crook or cop. Significant cross-modal priming occurred only for congruent role nouns (i.e., crook following She arrested the and cop following She was arrested by the). Current spreading activation accounts, which allow no influence of verbal voice, would incorrectly predict priming from arrested to crook and cop in all cases or would predict no priming at all.

In sentence-priming studies, Vu et al. (2003) used subject nouns, such as astronomer or director, to promote a situation model that led to disambiguating the meaning of a sentence-final word, such as star. They found that their manipulation was sufficient to activate selectively the dominant or subordinate meaning of the ambiguous noun. In this and other research (Vu, Kellas, \& Paul, 1998), the authors were careful to rule out a simple word association account of their results. Finally, Hess, Foss, and Carroll (1995) found that responses to sentence-final words were influenced more by their fit with the overall situation being described than by their association to specific words in the sentence. 
In summary, these are all compelling empirical phenomena for which basic word associations fail to provide insight into the results. In contrast, all of these results are well accounted for by the event representation expectancybased approach that we favor.

As a final alternative, spreading activation networks could be expanded by allowing noun nodes representing common agents, patients, instruments, and locations to become linked to corresponding verb nodes. These links might be formed through the learner's experience with events (e.g., noticing that chainsaws are used for cutting) and/or linguistic descriptions of events (through utterances in which chainsaw fills the instrument role of cut in speech and text). This structure would allow spreading activation networks to predict priming of verbs from typical thematic role fillers: When participants read a noun prime, activation could spread to the verb node, and priming would result. But in this case, the priming would be driven not by an undifferentiated word-associative link, but by a pattern of connectivity reflecting the underlying thematic relationship. Hence, a semantic network altered to encode event knowledge in these ways would no longer be a competing theory; instead, it would be one potential implementation of the event memory account for which we argue in this article.

\section{Implications for Sentence Processing}

Although short-SOA semantic priming has long indicated that word recognition rapidly activates lexicalsemantic knowledge, previous priming studies have not examined the types of lexical-semantic knowledge that are considered to be relevant to sentence comprehension. Here, we have shown that nouns, by activating events in semantic memory, are able to activate predictively verbs whose thematic roles they typically fill. These results support the hypothesis that during sentence comprehension, the processing of nouns leads to anticipatory semantic computation of the verbs (or semantic class of verbs) with which they may combine later in the sentence. Although the present study was not designed to test processing during sentence comprehension, it nonetheless offers an explanatory mechanism for studies that have shown anticipatory processing in sentential contexts.

Kamide et al. (2003), for example, have shown that nouns, in conjunction with other sentential information, play a role in predictively activating later nouns in the sentence. In an eye-tracking experiment, the authors showed that information from the subject NP and the verb, in combination, was able to constrain expectations for the object NP. A second study (in Japanese, a verb-final language) showed that case-marked preverbal nouns influenced the anticipation of other noun arguments, even when no information from the verb was yet available. Stronger evidence for the ability of context nouns alone to influence the activation of a generalized event comes from Altmann (1999). Participants read short paragraphs, such as "Giles had just finished dining in an expensive restaurant. He ordered some chocolates and cigars" and then saw "He drank ..." At the verb drink, although no anomaly had been encountered (it could easily continue as in "He drank some port while smoking his cigar"), the participants were more likely to report that the sentence did not make sense than they were when the context included ordered some brandy. One interpretation of these results (Altmann, 2002 ) is that the verb was anticipated on the basis of the entities introduced in the context and that, in the first context, the verb drank violated those expectancies. Similar influences of non-verb-based expectancies are found in English filler-gap constructions (Boland et al., 1989). All of these results can be understood on the basis of an account claiming that multiple elements of a sentence promote the computation of schematic event representations and that these are central to interpreting language. The degree to which each element may do so depends on the degree to which individual lexical concepts and their combinations constrain interpretation.

Although, to this point, we have focused on the activation of semantic knowledge, the conclusions we draw overlap a great deal with lexicalist proposals that syntactic knowledge is also associated with nouns (and other grammatical categories), as well as with the verb (Kim, Srinivas, \& Trueswell, 2002). As one example of a syntactic phenomenon, it is well established that verbs that can occur in more than one syntactic frame have a certain probability of occurring in each and that comprehenders are sensitive to these subcategorization biases, anticipating the structure that best fits the verb's bias (Garnsey et al., 1997; Hare, McRae, \& Elman, 2003, 2004; Trueswell, Tanenhaus, \& Kello, 1993). In fact, Trueswell and Kim (1998) showed, using a "fast priming" technique, that a verb that was briefly presented while participants read sentences influenced the readers' structural expectations. This phenomenon is not limited to verbs, however; certain nouns have syntactic frame requirements as well. In fact, Novick, Kim, and Trueswell (2003) showed, in a parallel study, that this information is activated when the noun is briefly flashed and influences structural expectations.

In summary, a wide range of research has focused on the important role of the verb both in constraining syntactic processing and in the construction of the situation models that are central to language comprehension. However, as the online interpretation of verb-final constructions implies, other elements of sentences can also serve as constraints in language processing. As Sanford and Garrod (1981) stated, "we use a linguistic input to call up representations of situations or events from long-term memory as soon as we have enough information to do so" (p. 115). The present experiments suggest that nouns that denote typical aspects of common events are often "enough information."

\section{REFERENCES}

Altmann, G. T. M. (1998). Ambiguity in sentence processing. Trends in Cognitive Sciences, 2, 146-152.

Altmann, G. T. M. (1999). Thematic role assignment in context. Journal of Memory \& Language, 41, 124-145.

Altmann, G. T. M. (2002). Predicting thematic role assignments in context. In P. Merlo \& S. Stevenson (Eds.), The lexical basis of sen- 
tence processing: Formal, computational, and experimental issues (pp. 281-302). Amsterdam: Benjamins.

Altmann, G. T. M., \& Kamide, Y. (1999). Incremental interpretation at verbs: Restricting the domain of subsequent reference. Cognition, 73, 247-264

Anderson, S. J., \& Conway, M. A. (1997). Representations of autobiographical memories. In M. A. Conway (Ed.), Cognitive models of memory (pp. 217-246). Cambridge, MA: MIT Press.

Becker, C. A. (1980). Semantic context effects in visual word recognition: An analysis of semantic strategies. Memory \& Cognition, 8 493-512.

Boland, J. E., Tanenhaus, M. K., Carlson, G., \& Garnsey, S. M. (1989). Lexical projection and the interaction of syntax and semantics in parsing. Journal of Psycholinguistic Research, 18, 563-576.

Brown, N. R., \& Schopflocher, D. (1998). Event clusters: An organization of personal events in autobiographical memory. Psychological Science, 9, 470-475.

Carlson, G. N., \& Tanenhaus, M. K. (1988). Thematic roles and language comprehension. In W. Wilkins (Ed.), Thematic relations (pp. 263-288). New York: Academic Press.

Christiansen, M., \& Chater, N. (1999). Toward a connectionist mode of recursion in human linguistic performance. Cognitive Science, 23, 157-205.

Cohen, J., MacWhinney, B., Flatt, M., \& Provost, J. (1993). PsyScope: An interactive graphic system for designing and controlling experiments in the psychology laboratory using Macintosh computers. Behavior Research Methods, Instruments, \& Computers, 25, 257-271.

Collins, A. M., \& Quillian, M. R. (1969). Retrieval time from semantic memory. Journal of Verbal Learning \& Verbal Behavior, 8 , 240-247

DE Groot, A. M. B. (1984). Primed lexical decision: Combined effects of the proportion of related prime-target pairs and the stimulus-onset asynchrony of prime and target. Quarterly Journal of Experimental Psychology, 36A, 253-280.

den Heyer, K., Briand, K., \& Dannenbring, G. L. (1983). Strategic factors in a lexical-decision task: Evidence for automatic and attention-driven processes. Memory \& Cognition, 11, 374-381.

DowTy, D. (1991). Thematic proto-roles and argument selection. Language, 67, 547-619.

Elman, J. L. (1990). Finding structure in time. Cognitive Science, 14, 179-211.

Elman, J. L., Hare, M., \& McRae, K. (2004). Cues, constraints, and competition in sentence processing. In M. Tomasello \& D. I. Slobin (Eds.), Beyond nature-nurture: Essays in honor of Elizabeth Bates (pp. 111-138). Mahwah, NJ: Erlbaum.

Federmeier, K. D., \& Kutas, M. (1999). A rose by any other name: Long-term memory structure and sentence processing. Journal of Memory \& Language, 41, 469-495.

FERreira, F., \& Clifton, C. (1986). The independence of syntactic processing. Journal of Memory \& Language, 25, 348-368.

FERretTI, T. R. (2000). Situation schemas, thematic roles and grammatical morphemes. Unpublished doctoral dissertation, University of Western Ontario.

Ferretti, T. R., McRae, K., \& Hatherell, A. (2001). Integrating verbs, situation schemas, and thematic role concepts. Journal of Memory \& Language, 44, 516-547.

Fillmore, C. J. (1968). The case for case. In E. Bach \& R. T. Harms (Eds.), Universals in linguistic theory (pp. 1-88). New York: Holt, Rinehart \& Winston.

FrazIER, L. (1987). Syntactic processing: Evidence from Dutch. Natural Language \& Linguistic Theory, 5, 519-560.

Frazier, L., Clifton, C., \& Randall, J. (1983). Filling gaps: Decision principles and structure in sentence comprehension. Cognition, 13, 187-222.

Garnsey, S. M., Pearlmutter, N. J., Myers, E., \& Lotocky, M. A. (1997). The contribution of verb-bias and plausibility to the comprehension of temporarily ambiguous sentences. Journal of Memory \& Language, 37, 58-93.

Garrod, S. C., \& SAnFord, A. J. (1981). Bridging inferences and the extended domain of reference. In J. [B.] Long \& A. [D.] Baddeley (Eds.), Attention and performance IX (pp. 331-346). Hillsdale, NJ: Erlbaum.
GENTNER, D. (1975). Evidence for the psychological reality of semantic components: The verbs of possession. In D. A. Norman \& D. E. Rumelhart (Eds.), Explorations in cognition (pp. 211-246). San Francisco: Freeman.

GentNeR, D. (1982). Why nouns are learned before verbs: Linguistic relativity versus natural partitioning. In S. Kuczaj II (Ed.), Language development: Vol. 2. Language, thought and culture (pp. 38-62). Hillsdale, NJ: Erlbaum.

Gruber, J. S. (1965). Studies in lexical relations. Unpublished doctoral dissertation, MIT, Cambridge, MA.

Hare, M., McRae, K., \& Elman, J. L. (2003). Sense and structure: Meaning as a determinant of verb subcategorization preferences. Journal of Memory \& Language, 48, 281-303.

Hare, M., McRae, K., \& Elman, J. L. (2004). Admitting that admitting verb sense into corpus analyses makes sense. Language \& Cognitive Processes, 19, 181-224.

Hare, M., McRae, K., Friedrich, J., Kelly, S., \& Thomson, C. (2005). Activating aspects of event knowledge from nouns denoting events, locations, and instruments. Manuscript in preparation.

Hess, D. J., Foss, D. J., \& CARroll, P. (1995). Effects of global and local context on lexical processing during language comprehension. Journal of Experimental Psychology: General, 124, 62-82.

Kahan, T. A., Neely, J. H., \& Forsythe, W. J. (1999). Dissociated backward priming effects in lexical decision and pronunciation tasks. Psychonomic Bulletin \& Review, 6, 105-110.

Kamide, Y., Altmann, G. T. M., \& Haywood, S. L. (2003). The timecourse of prediction in incremental sentence processing: Evidence from anticipatory eye movements. Journal of Memory \& Language, 49, 133-156

Kamide, Y., \& Mitchell, D. C. (1999). Incremental pre-head attachment in Japanese parsing. Language \& Cognitive Processes, 14, 631662

Kamide, Y., Scheepers, C., \& Altmann, G. T. M. (2003). Integration of syntactic and semantic information in predictive processing: Crosslinguistic evidence from German and English. Journal of Psycholinguistic Research, 32, 37-55.

Kim, A. E., Srinivas, B., \& Trueswell, J. C. (2002). The convergence of lexicalist perspectives in psycholinguistics and computational linguistics. In S. Stevenson \& P. Merlo (Eds.), The lexical basis of sentence processing (pp. 109-135). Amsterdam: Benjamins.

KolODNER, J. L. (1984). Retrieval and organizational strategies in conceptual memory: A computer model. Hillsdale, NJ: Erlbaum.

Kutas, M., \& Hillyard, S. A. (1984). Brain potentials during reading reflect word expectancy and semantic association. Nature, 307, 161-163.

LANCASTER, J. S., \& BARSAlou, L. W. (1997). Multiple organizations of events in memory. Memory, 5, 569-599.

MacDonald, M. C. (1994). Probabilistic constraints and syntactic ambiguity resolution. Language \& Cognitive Processes, 9, 157-201.

MacDonald, M. C., Pearlmutter, N. J., \& Seidenberg, M. S. (1994). The lexical nature of syntactic ambiguity resolution. Psychological Review, 101, 676-703.

Marslen-Wilson, W. D. (1975). Sentence perception as an interactive parallel process. Science, 189, 226-228.

Marslen-Wilson, W. D., \& Welsh, A. (1978). Processing interactions and lexical access during word recognition in continuous speech. $C o g$ nitive Psychology, 10, 29-63.

McRae, K., Ferretti, T. R., \& Amyote, L. (1997). Thematic roles as verb-specific concepts. Language \& Cognitive Processes, 12, 137 176.

McRae, K., Spivey-Knowlton, M. J., \& Tanenhaus, M. K. (1998). Modeling the influence of thematic fit (and other constraints) in online sentence comprehension. Journal of Memory \& Language, $\mathbf{3 8}$ 283-312.

Moss, H. E., Ostrin, R. K., Tyler, L. K., \& Marslen-Wilson, W. D. (1995). Accessing different types of lexical semantic information: Evidence from priming. Journal of Experimental Psychology: Learning, Memory, \& Cognition, 21, 863-883.

Myers, J. L. (1979). Fundamentals of experimental design. Boston: Allyn \& Bacon.

Novick, J. M., Kim, A., \& Trueswell, J. C. (2003). Studying the grammatical aspects of word recognition: Lexical priming, parsing, and 
syntactic ambiguity resolution. Journal of Psycholinguistic Research, 32, 57-75.

Peterson, R. R., \& Simpson, G. B. (1989). Effect of backward priming on word recognition in single-word and sentence contexts. Journal of Experimental Psychology: Learning, Memory, \& Cognition, 15, 1020-1032.

Pollatsek, A., \& Well, A. D. (1995). On the use of counterbalanced designs in cognitive research: A suggestion for a better and more powerful analysis. Journal of Experimental Psychology: Learning, Memory, \& Cognition, 21, 785-794.

Potts, G. R., Keenan, J. M., \& Golding, J. M. (1988). Accessing the occurrence of elaborative inferences: Lexical decision versus naming. Journal of Memory \& Language, 27, 399-415.

Rayner, K., Carlson, M., \& Frazier, L. (1983). The interaction of syntax and semantics during sentence processing. Journal of Verbal Learning \& Verbal Behavior, 22, 358-374.

Reiser, B. J., Black, J. B., \& ABELSON, R. P. (1985). Knowledge structures in the organization and retrieval of autobiographical memories. Cognitive Psychology, 17, 89-137.

Rumelhart, D. E., \& Levin, J. A. (1975). A language comprehension system. In D. A. Norman \& D. E. Rumelhart (Eds.), Explorations in cognition (pp. 179-208). San Francisco: Freeman.

SAG, I., \& WASOW, T. (1999). Syntactic theory: A formal introduction. Stanford, CA: CSLI Publications.

SANFORD, A. J., \& GARROD, S. C. (1981). Understanding written language: Explorations of comprehension beyond the sentence. Chichester, U.K.: Wiley.

SCHANK, R. C. (1982). Dynamic memory: A theory of reminding and learning in computers and people. New York: Cambridge University Press.

Spivey-Knowlton, M. J., \& Tanenhaus, M. K. (1998). Syntactic ambiguity resolution in discourse: Modeling the effects of referential context and lexical frequency. Journal of Experimental Psychology: Learning, Memory, \& Cognition, 24, 1521-1543.

Stolz, J. H., \& Neely, J. H. (1995). When target degradation does and does not enhance semantic context effects in word recognition. Journal of Experimental Psychology: Learning, Memory, \& Cognition, 21, 596-611.

Tabor, W., \& Tanenhaus, M. K. (2001). Dynamical systems for sentence processing. In M. H. Christiansen \& N. Chater (Eds.), Connectionist psycholinguistics (pp. 177-211). Westport, CT: Ablex.

Tanenhaus, M. K., Spivey-Knowlton, M. J., Eberhard, K. M., \& SEDIVY, J. C. (1995). Integration of visual and linguistic information in spoken language comprehension. Science, 268, 1632-1634.
Tanenhaus, M. K., \& Trueswell, J. C. (1995). Sentence comprehension. In J. L. Miller \& P. D. Eimas (Eds.), Speech, language, and communication (Handbook in Perception and Cognition, Vol. 11, pp. 217 262). San Diego: Academic Press.

Tomasello, M. (1992). First verbs: A case study of early grammatical development. Cambridge: Cambridge University Press.

Trueswell, J. C., \& Kim, A. (1998). How to prune a garden path by nipping it in the bud: Fast priming of verb argument structure. Journal of Memory \& Language, 39, 102-123.

Trueswell, J. C., Tanenhaus, M. K., \& Garnsey, S. M. (1994). Semantic influences on parsing: Use of thematic role information in syntactic ambiguity resolution. Journal of Memory \& Language, $\mathbf{3 3}$, 285-319.

Trueswell, J. C., Tanenhaus, M. K., \& Kello, C. (1993). Verbspecific constraints in sentence processing: Separating effects of lexical preference from garden-paths. Journal of Experimental Psychology: Learning, Memory, \& Cognition, 19, 528-553.

TruitT, T. P., \& ZwaAn, R. A. (1997, November). Verb aspect affects the generation of instrument inferences. Paper presented at the 38th Annual Meeting of the Psychonomic Society, Philadelphia.

Van Berkum, J. J. A., Brown, C. M., Zwitserlood, P., Kooljman, V., \& HaGoorT, P. (2005). Anticipating upcoming words in discourse: Evidence from ERPs and reading times. Journal of Experimental Psychology: Learning, Memory, \& Cognition, 31, 443-467.

Vu, H., Kellas, G., \& Paul, S. T. (1998). Sources of sentence constraint on lexical ambiguity resolution. Memory \& Cognition, 26, 979-1001.

Vu, H., Kellas, G., Petersen, E., \& Metcalf, K. (2003). Situationevoking stimuli, domain of reference, and the incremental interpretation of lexical ambiguity. Memory \& Cognition, 31, 1302-1315.

Wicha, N. Y. Y., Moreno, E. M., \& Kutas, M. (2003). Expecting gender: An event related brain potential study on the role of grammatical gender in comprehending a line drawing within a written sentence in Spanish. Cortex, 39, 483-508.

\section{NOTES}

1. See Ferretti et al. (2001) for a discussion of the point that it is a prototype-style concept that is activated, rather than words per se.

2 . The mask in Experiment 1 was actually unnecessary and was not used in Experiment 2, both for that reason and because it is undesirable with longer SOAs. The participants could easily perceive the $200-\mathrm{msec}$ prime, both with and without the mask. 
APPENDIX

\begin{tabular}{ll}
\multicolumn{2}{c}{ Agent-Verb Pairs } \\
actor & performing \\
assassin & killing \\
athlete & competing \\
audience & watching \\
burglar & stealing \\
butcher & cutting \\
carpenter & hammering \\
chauffeur & driving \\
chef & cooking \\
cop & arresting \\
detective & investigating \\
hero & rescuing \\
janitor & sweeping \\
judge & sentencing \\
lawyer & defending \\
maid & cleaning \\
merchant & selling \\
musician & composing \\
nun & praying \\
postman & delivering \\
professor & lecturing \\
reporter & interviewing \\
secretary & typing \\
sniper & shooting \\
spectator & cheering \\
surgeon & operating \\
thief & robbing \\
tourist & visiting \\
waiter & serving \\
witness & testifying \\
& \\
\hline &
\end{tabular}

\begin{tabular}{|c|c|}
\hline \multicolumn{2}{|c|}{ Instrument-Verb Pairs } \\
\hline axe & chopping \\
\hline broom & sweeping \\
\hline camera & photographing \\
\hline chainsaw & cutting \\
\hline crayon & coloring \\
\hline crutches & walking \\
\hline dagger & stabbing \\
\hline deadbolt & locking \\
\hline detergent & washing \\
\hline fork & eating \\
\hline furnace & heating \\
\hline hose & spraying \\
\hline keyboard & typing \\
\hline knife & slicing \\
\hline napkin & wiping \\
\hline needle & sewing \\
\hline oven & baking \\
\hline pen & writing \\
\hline pencil & drawing \\
\hline pistol & shooting \\
\hline rag & dusting \\
\hline razor & shaving \\
\hline rifle & hunting \\
\hline rod & fishing \\
\hline ruler & measuring \\
\hline shovel & digging \\
\hline soap & cleaning \\
\hline stopwatch & timing \\
\hline stove & cooking \\
\hline tinfoil & wrapping \\
\hline towel & drying \\
\hline toy & playing \\
\hline
\end{tabular}

\section{Patient-Verb Pairs}

\begin{tabular}{|c|c|}
\hline ball & thrown \\
\hline battery & charged \\
\hline book & read \\
\hline bottle & recycled \\
\hline cheque & cashed \\
\hline cigar & smoked \\
\hline clothes & worn \\
\hline coffee & brewed \\
\hline customer & served \\
\hline dice & rolled \\
\hline egg & fried \\
\hline evidence & examined \\
\hline fugitive & chased \\
\hline gift & opened \\
\hline god & worshipped \\
\hline guest & invited \\
\hline guitar & strummed \\
\hline hair & combed \\
\hline horse & ridden \\
\hline juice & drank \\
\hline lawn & mowed \\
\hline money & spent \\
\hline movie & rented \\
\hline puzzle & solved \\
\hline suspect & interrogated \\
\hline $\operatorname{tax}$ & paid \\
\hline teeth & brushed \\
\hline telephone & answered \\
\hline television & watched \\
\hline trailer & towed \\
\hline
\end{tabular}

Location-Verb Pairs

$\begin{array}{ll}\text { airport } & \text { flying } \\ \text { arena } & \text { skating } \\ \text { bathroom } & \text { showering } \\ \text { beach } & \text { tanning } \\ \text { bedroom } & \text { sleeping } \\ \text { cafeteria } & \text { eating } \\ \text { casino } & \text { gambling } \\ \text { church } & \text { worshipping } \\ \text { factory } & \text { working } \\ \text { garage } & \text { parking } \\ \text { gym } & \text { exercising } \\ \text { kitchen } & \text { cooking } \\ \text { library } & \text { studying } \\ \text { lineup } & \text { waiting } \\ \text { mall } & \text { shopping } \\ \text { park } & \text { playing } \\ \text { pool } & \text { swimming } \\ \text { pub } & \text { drinking } \\ \text { racetrack } & \text { betting } \\ \text { river } & \text { fishing } \\ \text { road } & \text { driving } \\ \text { sandbox } & \text { digging } \\ \text { sauna } & \text { sweating } \\ \text { school } & \text { learning } \\ & \\ & \end{array}$

(Manuscript received March 5, 2004;

revision accepted for publication November 11, 2004.) 